\title{
EPITELIECTOMÍA CONJUNTIVAL SECTORIAL Y TRASPLANTE DE MEMBRANA AMNIÓTICA EN INSUFICIENCIA LIMBAR PARCIAL
}

\author{
SECTORIAL CONJUNCTIVAL EPITHELIECTOMY AND \\ AMNIOTIC MEMBRANE TRANSPLANTATION FOR PARTIAL \\ LIMBAL STEM CELLS DEFICIENCY
}

\begin{abstract}
DÍAZ-VALLE D ${ }^{1}$, SANTOS-BUESO E ${ }^{1}$, BENÍTEZ-DEL-CASTILLO JM ${ }^{1}$, MÉNDEZ-FERNÁNDEZ R², LÓPEZ-ABAD C ${ }^{1}$, MARTÍNEZ-DE-LA-CASA JM ${ }^{1}$, GARCÍA-SÁNCHEZ J ${ }^{1}$
\end{abstract}

\section{RESUMEN}

Caso clínico: Varón de 74 años de edad desarrolló una insuficiencia limbar parcial secundaria a una causticación en el ojo izquierdo. Fue tratado mediante la realización de una epiteliectomía sectorial conjuntival asociada a injerto de membrana amniótica. 3 semanas más tarde existía un epitelio corneal íntegro, estable y regular.

Discusión: Este caso demuestra como la realización de una epiteliectomía sectorial asociada al injerto de membrana amniótica es un método eficaz y seguro para restaurar una superficie corneal estable en los casos de insuficiencia limbar parcial.

Palabras clave: Epitelio conjuntival, epitelio corneal, Limbo esclerocorneal, membrana amniótica, insuficiencia limbar.

\section{ABSTRACT}

Case report: A 74-year-old man developed a partial limbal stem cell deficiency secondary to a chemical injury in the left eye. He was treated with a sectorial conjunctival epitheliectomy and amniotic membrane transplantation. After 3 weeks there was an intact, smooth and stable corneal epithelium.

Discussion: This case report emphasizes that conjunctival epitheliectomy and amniotic membrane transplantation appears to be a safe and effective method of restoring a stable corneal epithelium for cases of partial limbal stem cell deficiency (Arch Soc Esp Oftalmol 2007; 82: 769-772).

Key words: Conjunctival epithelium, corneal epithelium, corneoscleral limbus, amniotic membrane, limbal insufficiency.

\footnotetext{
Recibido: 24/10/06. Aceptado: 17/9/07.

1 Doctor en Medicina.

2 Licenciado en Medicina.

Correspondencia:

David Díaz Valle

Unidad de Superficie e Inflamación Ocular

Hospital Clínico Universitario San Carlos

C/. Martín Lagos, s/n

Madrid

España

E-mail: daviddiazvalle@yahoo.es
}

Unidad de Superficie e Inflamación Ocular. Hospital Clínico Universitario San Carlos. Madrid. España. 


\section{INTRODUCCIÓN}

En el limbo esclerocorneal, a nivel de las empalizadas de Vogt, se encuentra una población celular epitelial conocida como células madre limbares. Se cree que estas células serían las responsables de la función regeneradora que permite el mantenimiento del epitelio corneal y de la función de barrera frente a la migración de las células conjuntivales sobre la córnea (1). La pérdida de dichas funciones se conoce como insuficiencia limbar (IL), y puede ser consecuencia de la destrucción directa de dicha población celular o de su microambiente estromal. Histopatológicamente, la IL se caracteriza por la existencia de conjuntivalización con presencia de células caliciformes sobre la córnea, vascularización, destrucción de la membrana basal corneal e inflamación crónica (2).

El tratamiento de la IL total requiere trasplantar una cantidad suficiente de células madre limbares para conseguir la reepitelización corneal con células con el fenotipo adecuado. En la IL parcial, Dua ha demostrado la utilidad de realizar un desbridamiento del epitelio conjuntival que recubre la córnea con el objetivo de que la zona denudada sea cubierta por un epitelio de características corneales procedente de las zonas limbares indemnes, técnica que ha denominado epiteliectomía conjuntival sectorial (ECS) (3). Otros autores como Anderson et al (4) han realizado la técnica asociada a un trasplante de membrana amniótica (TMA) para facilitar el mantenimiento y la expansión de las células epiteliales limbares. Según estos autores, el procedimiento combinado ofrece unos resultados superiores a los desbridamientos repetidos de la superficie corneal conjuntivalizada, si bien persiste el riesgo de que se produzcan fracasos tardíos de la superficie ocular.

Presentamos el caso de un paciente de 74 años con una insuficiencia limbar parcial unilateral de larga evolución que fue tratado con éxito mediante ECS asociada a TMA.

\section{CASO CLÍNICO}

Paciente varón de 74 años consulta por cuadros recurrentes de ojo rojo doloroso en OI, asociados a una pérdida progresiva de visión de varios meses de evolución. No refiere antecedentes personales sistémicos relevantes. Como antecedentes oftálmicos destaca la exposición accidental a un producto de limpieza 15 años antes.

En la exploración oftalmológica se objetivó una agudeza visual (AV) de 8/10 en ojo derecho (OD) y $1 / 10$ en ojo izquierdo (OI). En la exploración biomicroscópica destacaba en OI la existencia de un área de aproximadamente $210^{\circ}$ de conjuntivalización corneal que afectaba el eje visual, con vascularización superficial e hiperemia mixta (fig. 1). Existía un sector de limbo de aproximadamente 5 horas de extensión que conservaba la arquitectura normal de las empalizadas de Vogt y una ausencia de tinción con colorantes. El resto de la exploración no mostraba hallazgos relevantes.

Con el diagnóstico clínico de IL parcial con afectación del eje visual se practicó una ECS del tejido fibrovascular que invadía la superficie corneal, incluyendo la zona limbar afecta, y respetando el sector de limbo nasal de características normales. En la zona denudada se colocó un injerto de membrana amniótica (MA) que se suturó con el epitelio hacia arriba y posteriormente otro fragmento circular de MA de $15 \mathrm{~mm}$ de diámetro que se suturó como parche, con el epitelio hacia abajo (fig. 2). Durante el seguimiento se produjo una reepitelización progresiva con un epitelio de características corneales sobre el injerto de MA que quedó integrado bajo el mismo (fig. 3). A las 3 semanas de la cirugía existía una superficie corneal epitelial lisa y regular y una importante reducción de la hiperemia mixta asociada (fig.4). La AV del OI mejoró hasta

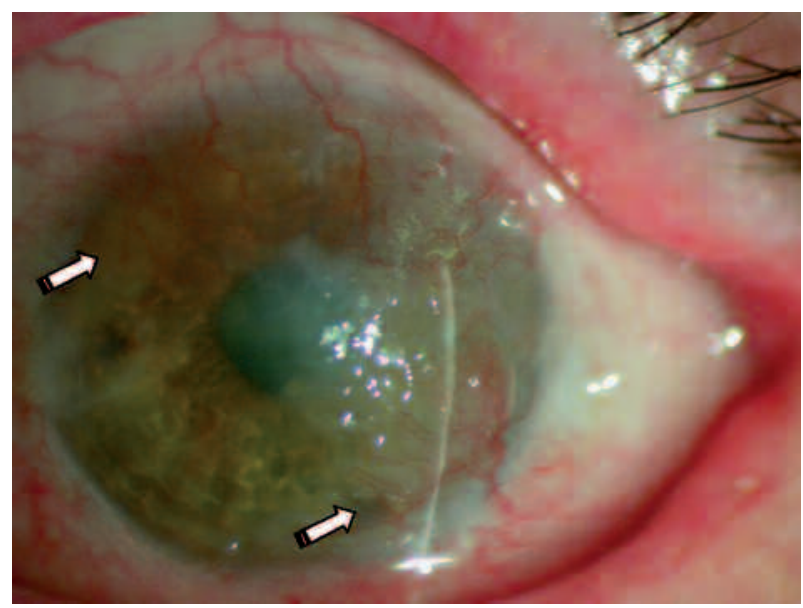

Fig. 1: Insuficiencia limbar parcial de aproximadamente 7 horas $\left(210^{\circ}\right)$ de extensión (flechas blancas). Nótese la existencia de una ruptura de las empalizadas de Vogt, vascularización e hiperemia crónica. 


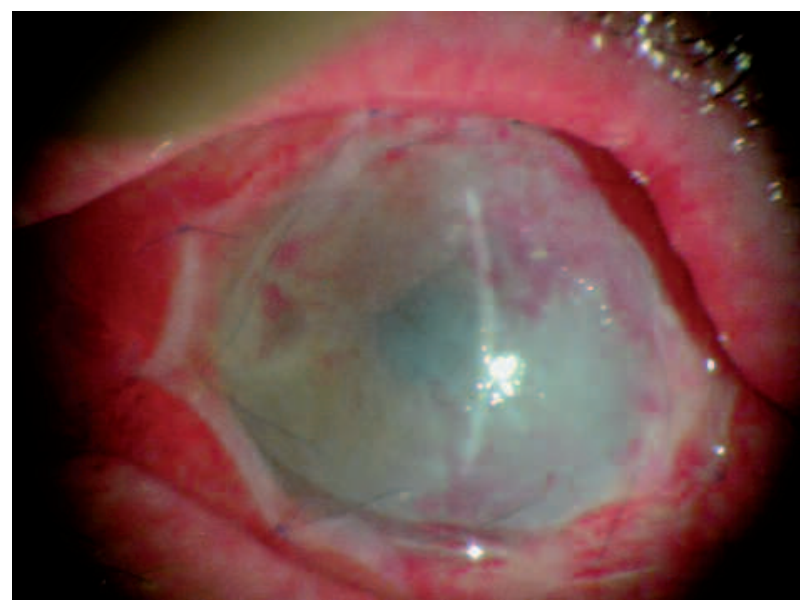

Fig. 2: Epiteliectomía sectorial asociada a injerto de membrana amniótica. Día 1 del postoperatorio. Se ha colocado una doble capa de membrana amniótica, la primera de ellas como injerto con el epitelio hacia arriba servirá como membrana basal y la segunda como parche o lente de contacto biológica, con el lado estromal hacia arriba.

4/10. Con un seguimiento de 8 meses no se han observado recidivas.

\section{DISCUSIÓN}

El fundamento de realizar una ECS se basa en que los defectos epiteliales corneales extensos con afectación limbar pueden regenerse a partir de la migración celular desde las áreas epiteliales indemnes,

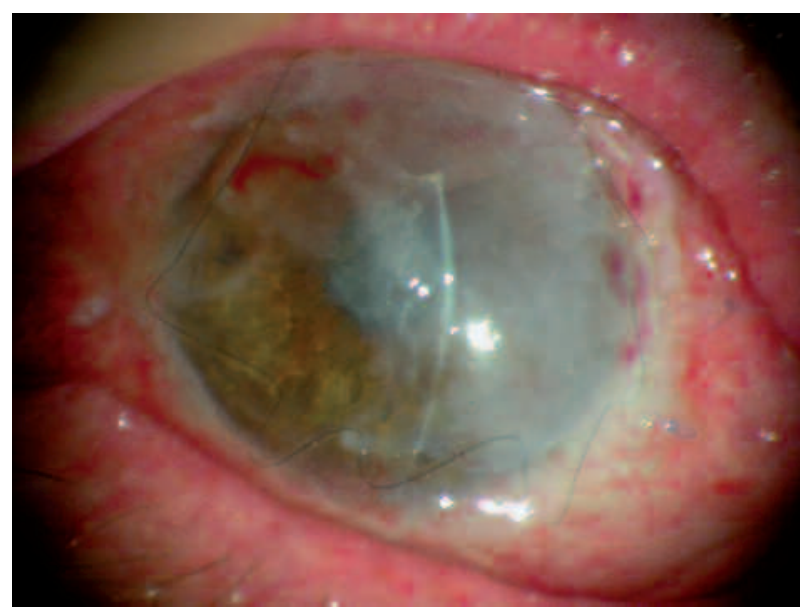

Fig. 3: Reepitelización progresiva sobre el injerto de membrana amniótica.

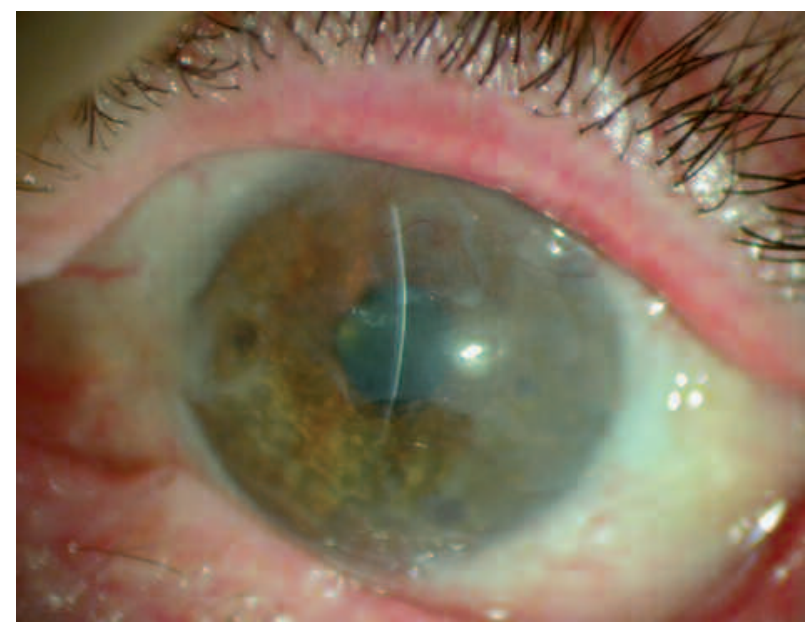

Fig. 4: A las 3 semanas se observa un epitelio de características corneales de aspecto liso y regular y una marcada reducción de la hiperemia mixta asociada.

mientras que las células limbares pueden experimentar una migración circunferencial desde los dos extremos del área limbar sana intentado recubrir toda la extensión limbar. Sin embargo, esta migración queda inhibida cuando una zona de epitelio conjuntival atraviesa el limbo y contacta con el epitelio limbar proliferante (5). Se ha estimado que un $25 \%$ del limbo indemne sería suficiente para repoblar toda la superficie corneal. En los casos en los que el área limbar sana sea inferior a 3 horas, la estrategia debería únicamente dirigirse a la desepitelización exclusiva del área corneal central con la finalidad de que ésta pudiera ser recubierta por un epitelio normal a expensas del limbo funcionante (3).

El efecto beneficioso de asociar un TMA se basa en la restauración de una membrana basal intacta que suele estar lesionada en la IL. La MA es un sustrato ideal que facilita la adhesión, diferenciación y expansión de las células epiteliales proliferantes, así como suprime la apoptosis celular. La porción estromal de la MA también aporta una serie de beneficios adicionales debido a sus efectos antiinflamatorios y antiangiogénicos, así como a la liberación de numerosos factores de crecimiento e inhibidores de proteasas (4).

En conclusión, el caso que presentamos confirma la utilidad de realizar una ECS y asociar un TMA para lograr la reepitelización corneal, al menos a medio plazo, a partir de las áreas limbares sanas en IL parciales extensas pero en las que existe más de un $25 \%$ del limbo indemne. 


\section{BIBLIOGRAFÍA}

1. Dua HS, Azuara-Blanco A. Limbal stem cells of the corneal epithelium. Surv Ophthalmol 2000; 44: 415-425.

2. Puangsricharern V, Tseng SC. Cytologic evidence of corneal diseases with limbal stem cell deficiency. Ophthalmology 1995; 102: 1476-1485.

3. Dua HS. Sequential sectoral conjunctival epitheliectomy
(SSCE). En: Holland EJ, Mannis MJ . Ocular Surface disease. New York: Springer-Verlag; 2002; 168-174.

4. Anderson DF, Ellies P, Pires RT, Tseng SC. Amniotic membrane transplantation for partial stem cell deficiency. Br J Ophthalmol 2001; 85: 567-575.

5. Dua HS, Forrester JV. The corneoscleral limbus in human corneal epithelial wound healing. Am J Ophthalmol 1990; 110: 646-656. 